\title{
Reexamining treatment of high-grade T1 bladder cancer according to depth of lamina propria invasion: a prospective trial of $\mathbf{2 0 0}$ patients
}

A Orsola*,1 ${ }^{*}$ L Werner ${ }^{2}$, I de Torres ${ }^{3}$, W Martin-Doyle ${ }^{4}$, C X Raventos ${ }^{5}$, F Lozano ${ }^{5}$, S A Mullane ${ }^{1}$, J J Leow ${ }^{6,7}$, J A Barletta ${ }^{8}$, J Bellmunt ${ }^{1}$ and $\mathrm{J} \mathrm{Morote}^{1}$

${ }^{1}$ Department of Oncology, Dana-Farber/Brigham and Women's Hospital Cancer Center, Harvard Medical School, Boston, MA 02215, USA; ${ }^{2}$ Departments of Biostatistics and Computational Biology, Dana-Farber Cancer Institute, Harvard Medical School, Boston, MA 02215, USA; ${ }^{3}$ Department of Pathology, Vall d'Hebron Hospital, Barcelona 08035, Spain; ${ }^{4}$ University of Massachusetts Medical School, Worcester, MA 01655, USA; ${ }^{5}$ Department of Urology, Vall d'Hebron Hospital, Barcelona 08035, Spain; ${ }^{6}$ Center for Surgery and Public Health, Brigham and Women's Hospital, Boston, MA 02215, USA; ${ }^{7}$ Division of Urology, Brigham and Women's Hospital, Boston, MA 02215, USA and ${ }^{8}$ Department of Pathology, Dana-Farber/Brigham and Women's Hospital Cancer Center, Harvard Medical School, Boston, MA 02215, USA

Background: Management of high-grade T1 (HGT1) bladder cancer represents a major challenge. We studied a treatment strategy according to substaging by depth of lamina propria invasion.

Methods: In this prospective observational cohort study, patients received initial transurethral resection (TUR), mitomycin-C, and BCG. Subjects with shallower lamina propria invasion (HGT1a) were followed without further surgery, whereas subjects with HGT1b received a second TUR. Association of clinical and histological features with outcomes (primary: progression; secondary: recurrence and cancer-specific survival) was assessed using Cox regression.

Results: Median age was 71 years; 89.5\% were males, with 89 (44.5\%) cases T1a and 111 (55.5\%) T1b. At median follow-up of 71 months, disease progression was observed in 31 (15.5\%) and in univariate analysis, substaging, carcinoma in situ, tumour size, and tumour pattern predicted progression. On multivariate analysis only substaging, associated carcinoma in situ, and tumour size remained significant for progression.

Conclusions: In HGT1 bladder cancer, the strategy of performing a second TUR only in T1b cases results in a global low progression rate of $15.5 \%$. Tumours deeply invading the lamina propria (HGT1b) showed a three-fold increase in risk of progression. Substaging should be routinely evaluated, with HGT1b cases being thoroughly evaluated for cystectomy. Inclusion in the TNM system should also be carefully considered.

Over 150000 and 72000 new cases of bladder cancer (BC) are estimated to be diagnosed each year in Europe and the United States, respectively (Ferlay et al, 2013). When initially diagnosed, most are non-muscle invasive (NMIBC); that is, either non-invasive and confined to the mucosa (Ta and carcinoma in situ (CIS)) or invading the lamina propria (LP) but not yet the detrusor muscle (T1).

T1 of high cellular grade (HGT1), the subset of NMIBC with the highest risk of progression, may exhibit histopathological, clinical, 
and biological characteristics of invasive tumours. Even though classically $30 \%$ of these tumours have been considered to progress (Sylvester et al, 2006), updated data show a $21 \%$ progression rate (van den Bosch and Alfred Witjes, 2011). Therefore, a notable proportion of HGT1 behave in a relatively indolent manner and up to one-third resolve ad integrum after standard treatment (Pansadoro et al, 2002; Jakse et al, 2004). This wide range of tumour biology highlights the need to risk stratify these patients. Unfortunately, for high-risk NMIBC, both EORTC and CUETO scoring systems have poor discriminating ability and limited predictive value, tending to overestimate progression (van den Bosch and Alfred Witjes, 2011; Xylinas et al, 2013).

As a result, there is a need to reexamine management of HGT1 BC. Standard initial treatment is based on endoscopic transurethral resection (TUR), and intravesical immunotherapy with BCG. A repeat resection (reTUR) is recommended by guidelines to rule out understaging (American Urological Association, 2007; Babjuk et al, 2013), even though for an array of reasons, reTUR remains underutilised with no higher than $7.7 \%$ of HGT1 patients reportedly undergoing this second procedure even at tertiary care centres (Skolarus et al, 2011). ReTUR may improve outcome (Herr et al, 2007) but adds morbidity and is probably unnecessary in over $60 \%$ of cases, while $6.5-30 \%$ might still progress (Divrik et al, 2010; Sfakianos et al, 2014). Conversely, prolongation of conservative treatment and deferring radical cystectomy may allow progression and decrease cancer-specific survival (CSS) (Raj et al, 2007, Divrik et al, 2010). Deciding upon ideal timing for cystectomy is one of the most difficult clinical decisions in urology and an ongoing area of controversy. This major surgical procedure requires urinary diversion, is associated with substantial morbidity (50- 67\% complication rate) and up to $9 \%$ mortality (Aziz et al, 2013), and may represent overtreatment (Pansadoro et al, 2002). Therefore, identifying those cases of HGT1 suitable for organ preservation and differentiating them from those that will most benefit from a timely cystectomy is a major challenge and key to improving outcomes.

Our group has been working to improve treatment strategy in HGT1 BC and, with others, has shown that substaging HGT1 according to the depth of LP invasion allows identification of patients at low (T1a) and high (T1b) risk of progression (Orsola et al, 2005; Rouprêt et al, 2013). Based on this evidence and to optimise resources, we designed a strategy by which a second TUR was indicated only in patients with deep LP invasion (T1b). In addition, because BCG response is also a strong predictor of progression, the second TUR was performed after a course of BCG induction. In the preliminary report of this series (Orsola et al, 2010), we showed that tumour size $>3 \mathrm{~cm}$ and associated CIS predict positive findings in the first evaluation at 3 months and speculated that HGT1a cases can safely forgo a second TUR.

In this study, we present the mature results of the first 200 cases of initial HGT1 treated with this optimised approach, at 71 months median follow-up, assessing recurrence, progression, and CSS, as well as evaluating clinical and histological features as prognostic factors.

\section{MATERIALS AND METHODS}

Trial design and inclusion of this prospective observational cohort study began in April 2005. Since then, patients diagnosed at initial TUR with HGT1 BC were offered entry into this protocol. Transurethral resection BT included complete resection of all visible tumours, with a separate base biopsy. Cold cup biopsies to detect CIS were taken, depending on surgeon preference, in a standardised manner or according to EAU Guidelines (abnormal urothelium, non-papillary tumour appearance, or positive cytology) (Babjuk et al, 2013). All patients received a postoperative dose of intravesical mitomycin-C.

Tumours were graded according to the 2004 WHO system (2006) after pathological assessment of the total specimen. A twotier system (Cottrell et al, 2007) was used to assess the depth of LP invasion: T1a when tumour involved the subepithelial connective tissue superficial to muscularis mucosae (MM); T1b when tumour was found at the level of or beyond MM. When MM was not identifiable, thick-walled blood vessels deep in LP served as a landmark, or alternatively location of MM in tumour-free tissue of the same TUR was used for reference. Only initial HGT1 tumours with a visible, clearly identifiable and disease-free muscularis propria were included in this study. Patients with LP invasion (T1) but without muscularis propria in the specimen represent $\sim 10 \%$ of all T1 in our centre. These cases, identified as Tx, did not fulfill the requirements to enter this protocol and, following guidelines, directly underwent a repeat resection.

This protocol was approved by the Hospital Ethics Committee and registered at clinicaltrials.gov (NCT02113501), and last evaluation of patients was performed in February 2014. Enrolled subjects received six weekly instillations of $2-8 \times 10^{8}$ UFC BCGTice (OncoTICE, Schering-Plough Canada Inc., Kirkland, QC, Canada) and, at 3 months after initial TUR, underwent either a second TUR post-BCG (T1b) or a cystoscopy plus cytology (T1a). Follow-up included BCG maintenance; the strategy is summarised in Figure 1 and described in detail in our previous report (Orsola et al, 2010). Baseline characteristics were compared between the T1a and T1b groups using Fisher's exact test.

The primary objective was the assessment of progression, recurrence, and CSS. Progression was defined as occurrence of an invasive tumour at post-BCG TUR, the development of muscle invasive or more advanced stage carcinoma, distant metastasis, or death from BC. Time to progression was defined as time from diagnosis of $\mathrm{BC}$ to the date when disease progression was observed, or censored on the last known date alive without progression. Recurrence was defined as the first evidence of any NMIBC detected on follow-up. Time to recurrence was defined as time from diagnosis of $\mathrm{BC}$ to the date when disease recurrence was observed, or censored at the last known date alive without disease recurrence, or at date of progression. Cancer-specific survival was defined as death from the same cancer or related causes.

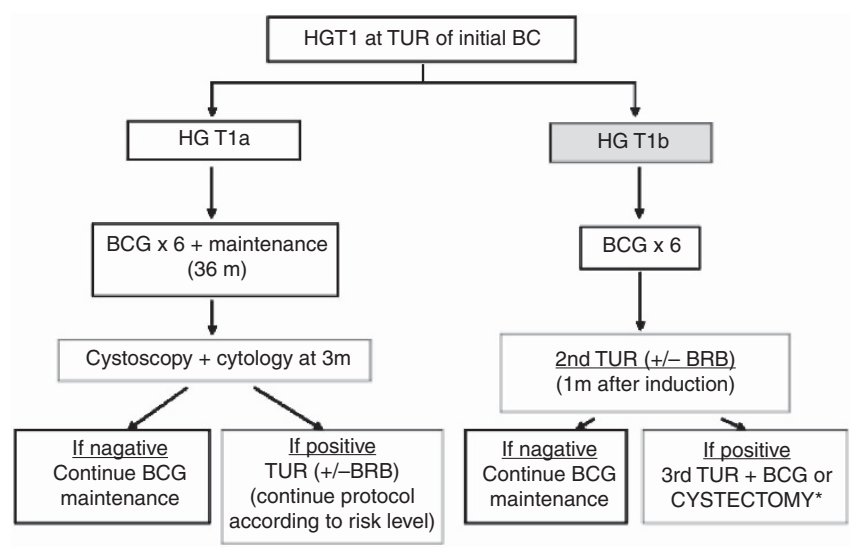

Figure 1. Summary of the protocol. For all patients with positive findings at 3 months, the final decision about treatment, including the option of cystectomy, was taken according to disease status and the patient's preference. Fourteen percent cases did not receive immediate MitC post-TUR. BCG maintenance schedule consisted of three weekly instillations of Oncotice at 3 months and every 6 months thereafter (for 2-3 years depending on tolerance). *According to physician advice and patients choice. Abbreviations: $\mathrm{BRB}=$ bladder random biopsies; $T U R=$ trans urethral resection. 
The secondary objective was the assessment of prognostic factors. Eleven clinical and pathological variables were prospectively documented to evaluate their capacity to predict events. Kaplan-Meier analysis was used to summarise median time to recurrence and time to progression. Association of time to recurrence, time to progression, and CSS with the variables of interest was assessed using Cox regression models in univariate and multivariable models, reporting hazard ratios (HRs) and 95\% CI.

\section{RESULTS}

Two hundred primary urothelial HGT1 cases have been identified at TUR and have entered the present protocol. Median age at diagnosis was 71 years; $89.5 \%$ were males, with 89 (44.5\%) cases being T1a and 111 (55.5\%) T1b. Patients and tumour characteristics are shown in Table 1 classified by substaging. The median follow-up period was 71 months (range: 5-107 months). The second TUR (performed only in T1b) was negative in $67.5 \%$ of cases and positive in the remaining 32.4\% (11 invasive and 25 noninvasive; primary histology being persistent HGT1). Tolerance and patient dropout of BCG was not documented specifically within the study group, but for the broader population of high-risk BC at our hospital $\sim 30 \%$ do not complete the first year.

Table 1. Association of clinical and histological variables with substaging (T1a vs T1b)

\begin{tabular}{|c|c|c|c|c|}
\hline & T1a & T1b & Total & $P$ \\
\hline Age (years) $(<70 / \geqslant 70)$ & $44 / 45$ & $52 / 59$ & $96 / 104$ & 0.78 \\
\hline Gender: Male/Female & $79 / 10$ & $100 / 11$ & 179/21 & 0.82 \\
\hline Tumour size: $<3 \mathrm{~cm} />3 \mathrm{~cm}$ & $55 / 34$ & $59 / 52$ & $114 / 86$ & 0.14 \\
\hline Tumour number: solitary/multiple & $49 / 40$ & $60 / 51$ & 109/91 & $>0.99$ \\
\hline Tumour pattern: papillary/solid & $84 / 5$ & $82 / 29$ & $166 / 34$ & 0.0001 \\
\hline Lymphovascular invasion: yes/no & $1 / 88$ & $6 / 105$ & 7/193 & 0.09 \\
\hline Micropapillary ${ }^{a}$ : yes/no & $3 / 86$ & $12 / 99$ & $15 / 185$ & 0.06 \\
\hline Squamous metaplasia: yes/no & $21 / 68$ & $40 / 71$ & $61 / 139$ & 0.06 \\
\hline $\mathrm{ClS}^{\mathrm{a}}:$ yes$/ \mathrm{no}$ & $17 / 72$ & $40 / 71$ & $57 / 143$ & 0.01 \\
\hline CIS in prostate $:$ yes/no & $0 / 79$ & $7 / 93$ & $7 / 172$ & 0.02 \\
\hline
\end{tabular}

Abbreviation: $\mathrm{CIS}=$ carcinoma in situ. Subjects with $\mathrm{T} 1 \mathrm{~b}$ disease presented with significantly higher rates of solid pattern, associated bladder CIS and prostate CIS.

$\mathrm{a}_{133}$ Patients underwent random bladder biopsies.

bonly evaluated in male patients.
Recurrence was observed in 57 (28.5\%) patients and disease progression in 31 (15.5\%). In total, 46 patients died (13 of BC, 14 of other cancers, 18 of other causes, and one of unknown cause) and 18 underwent cystectomy ( 2 pT0, 1 pT1, 4 pTIS, 3 pT2, 4 pT3, and 3 pT4; one cystectomy at another centre; and 3 presented with positive lymph nodes). Ten potential candidates for cystectomy received palliative treatment because they were considered ineligible due to high surgical and/or anaesthetic risk.

The association of relevant clinical and pathological variables with time to progression and recurrence is presented in Table 2. Median time to recurrence was not reached; 2- and 5-year recurrence-free rates are summarised. Recurrence rate was not significantly different among HGT1a (21 cases, 22\%) and HGT1b (36 cases, $34.6 \%$ ), with only age at diagnosis remaining significant on multivariate analysis. Table $3 \mathrm{a}$ and $\mathrm{b}$ summarise univariate and multivariate analysis for recurrence.

Progression rate demonstrated a significant difference based on substaging, with HGT1b tumours showing an increased risk of progression (5 T1a (5.6\%) vs $26 \mathrm{~T} 1 \mathrm{~b}(23.6 \%))$. Median time to progression was not reached; the 2- and 5-year progression-free rates are summarised in Table $4 \mathrm{a}$. Variables significant in univariate analysis together with lymphovascular invasion (LVI) and gender (significant in previous publications, but not in the current univariate analysis) were evaluated in a multivariable model for time to progression (Table $4 \mathrm{~b}$ ). Substaging, CIS, and tumour size remained significant in this model. Figure 2 illustrates the Kaplan-Meier curves for progression in relation to substaging, tumour pattern, tumour size, and associated CIS.

The low number of deaths due to BC precluded analysis of predictors of CSS. Five-year CSS was 99\% for T1a and 95\% for T1b. Of the 13 patients who died due to $\mathrm{BC}$ ( 3 of local progression (no cystectomy) and 10 from metastatic BC, 6 of which had undergone cystectomy) all except one were originally T1b.

Finally, the association of TIS and tumour size in deeply invasive cases (T1b) gave an HR for progression of 4.81 with $95 \%$ CI $(2.07,11.20)(P=0.0003)$ for patients with T1b + CIS $+>3 \mathrm{~cm}$ compared with the rest.

\section{DISCUSSION}

In HGT1 BC, the proposed strategy of deferring a second TUR until after induction of BCG and doing so only in T1b cases, results in a global low progression rate of $15.5 \%$. Cases in which tumours invaded the MM (T1b) had a three-fold increased risk of

Table 2. Univariate analysis for association of clinically and pathologically relevant variables with time to recurrence and time to progression

\begin{tabular}{|c|c|c|c|c|}
\hline & Recurren & & Progressi & \\
\hline & Hazard ratio $(95 \% \mathrm{Cl})$ & $P$ & Hazard ratio $(95 \% \mathrm{Cl})$ & $P$ \\
\hline Age (years) $<70 / \geqslant 70$ & $0.5(0.29,0.86)$ & 0.01 & $0.59(0.29,1.22)$ & 0.15 \\
\hline Gender: Male/Female & $0.81(0.37,1.78)$ & 0.59 & $1.09(0.33,3.59)$ & 0.89 \\
\hline Tumour size: $<3 \mathrm{~cm} />3 \mathrm{~cm}$ & $0.59(0.35,0.99)$ & 0.04 & $0.44(0.22,0.91)$ & 0.02 \\
\hline Tumour number: solitary/multiple & $0.68(0.40,1.14)$ & 0.14 & $0.66(0.33,1.34)$ & 0.25 \\
\hline Tumour pattern: papillary/solid & $0.76(0.39,1.47)$ & 0.41 & $0.37(0.17,0.78)$ & 0.006 \\
\hline Lymphovascular invasion: yes/no & $2.63(0.95,7.27)$ & 0.06 & $3.11(0.94,10.28)$ & 0.06 \\
\hline Micropapillary*: yes/no & $0.69(0.23,2.21)$ & 0.53 & $0.99(0.24,4.19)$ & 0.99 \\
\hline Squamous metaplasia: yes/no & $1.18(0.68,2.04)$ & 0.57 & $1.00(0.46,2.17)$ & 0.99 \\
\hline CIS: yes/no & $0.71(0.41,1.25)$ & 0.23 & $0.23(0.46,2.17)$ & $<0.0001$ \\
\hline $\mathrm{CIS}$ in prostate: yes/no & $0.84(0.20,3.44)$ & 0.80 & $0.45(0.11,1.88)$ & 0.26 \\
\hline Substaging: $T 1 \mathrm{a} / \mathrm{T} 1 \mathrm{~b}$ & $0.61(0.36,1.04)$ & 0.07 & $0.21(0.08,0.54)$ & 0.0004 \\
\hline
\end{tabular}


Table 3a. Univariate analysis for recurrence; association of tumour size and age at diagnosis with time to recurrence at 2 and 5 years (only showing variables with significant $P$-values)

\begin{tabular}{|c|c|c|c|c|c|c|}
\hline & $N$ & Recur & $\begin{array}{c}\text { Recurrence free } \\
\text { at } 2 \text { years }\end{array}$ & $\begin{array}{c}\text { Recurrence free } \\
\text { at } 5 \text { years }\end{array}$ & $\begin{array}{l}\text { Hazard ratio and } \\
\qquad 95 \% \mathrm{Cl}\end{array}$ & $P$ \\
\hline Tumour size & & & & & & 0.04 \\
\hline $\begin{array}{l}<3 \mathrm{~cm} \\
>3 \mathrm{~cm}\end{array}$ & $\begin{array}{r}113 \\
86\end{array}$ & $\begin{array}{l}27 \\
30\end{array}$ & $\begin{array}{l}0.81(0.72,0.87) \\
0.72(0.60,0.80)\end{array}$ & $\begin{array}{l}0.76(0.67,0.83) \\
0.59(0.46,0.70)\end{array}$ & $\begin{array}{c}0.59(0.35,0.99) \\
1 \text { (reference) }\end{array}$ & \\
\hline Age at $d x$ & & & & & & 0.01 \\
\hline $\begin{array}{l}<70 \\
\geqslant 70\end{array}$ & $\begin{array}{r}96 \\
103 \\
\end{array}$ & $\begin{array}{l}20 \\
37 \\
\end{array}$ & $\begin{array}{l}0.85(0.76,0.91) \\
0.70(0.59,0.78)\end{array}$ & $\begin{array}{l}0.78(0.67,0.85) \\
0.58(0.47,0.69) \\
\end{array}$ & $\begin{array}{c}0.50(0.29,0.86) \\
1 \text { (reference) }\end{array}$ & \\
\hline
\end{tabular}

Table 3b. Multivariable analysis for recurrence; association of CIS, substaging, tumour size, tumour pattern, lymphovascular invasion and gender with time to recurrence

\begin{tabular}{|l|c|c|}
\hline & $\begin{array}{c}\text { Hazard ratio and } \\
\mathbf{9 5 \%} \mathrm{Cl}\end{array}$ & $\boldsymbol{P}$ \\
\hline Substaging (T1a) & $0.64(0.37,1.14)$ & 0.13 \\
\hline CIS (No) & $0.68(0.38,1.21)$ & 0.19 \\
\hline Size $(<3 \mathrm{~cm})$ & $0.59(0.34,1.01)$ & 0.06 \\
\hline Pattern (papillary) & $1.12(0.53,2.37)$ & 0.78 \\
\hline Lymphovascular invasion (yes) & $2.16(0.71,6.59)$ & 0.18 \\
\hline Gender (male) & $0.81(0.36,1.81)$ & 0.60 \\
\hline Age $(<70$ years) & $0.50(0.29,0.87)$ & 0.01 \\
\hline A & &
\end{tabular}

Abbreviations: $\mathrm{Cl}=$ confidence interval; $\mathrm{ClS}=$ carcinoma in situ. $\mathrm{P}<0.05$ represent statistically significant values (shown in bold).

progression compared with those without MM invasion (T1a), even though the latter group was treated more conservatively. Our report goes on to confirm the role of CIS, tumour size, and tumour pattern as prognostic factors for worse outcomes in this group of high-risk non-muscle invasive BC.

To the best of our knowledge, this is the first report addressing the role of substaging HGT1 BC prospectively to guide therapeutic management. This novel strategy, together with the relatively large number of cases of initial HGT1, the long follow-up and the consistent treatment approach are the main strengths of our series. In addition, the evaluation of depth of tumour invasion was performed prospectively after TUR as part of the routine pathological report, whereas most reports on HGT1 are retrospective and observational. We cannot rule out bias due to patient selection since cases with recurrent tumours and those with no muscularis propria identified were not included; our series might also include some G2 cases (WHO 1974 classification) under the broader definition of HG BC. On the other hand, tumours that could have been understaged (early progressors or positive second TUR) were not excluded from the analysis in the understanding that this represents a more generalisable real-world practice, but might also be seen as a bias. Finally, our results are limited by the fact that the study was performed in a non-randomised manner. This limitation is widespread in the high-risk BC literature as most reports have retrospective observational designs, with few randomised studies (Martin-Doyle et al, 2014). Given the public nature of our health-care system, we chose to differentially allocate patients to treatment, using a more aggressive approach for $\mathrm{T} 1 \mathrm{~b}$ tumours, aiming to optimise resources.

The role of substaging has been well established throughout the past 20 years, with over 2500 published cases substaged according to invasion of the MM (Rouprêt et al, 2013). The relevance of this factor has been recently confirmed in the largest meta-analysis ever conducted on prognostic factors in HGT1 (Martin-Doyle et al, 2014). Because the evaluation of the depth of invasion is subject to interobserver and intraobserver variability, this parameter has been criticised for the last two decades, but there is growing evidence on the reproducibility of this evaluation. In a study specifically addressing this issue, Cottrell et al (2007) elegantly showed a high concordance rate among general pathologists after guidance based only in a presentation of the staging systems as described by the SIGN guideline. In their report, the median $\mathrm{K}$ concordance rate was 0.623 , which is higher than that attained for Gleason score among pathologists (Bottke et al, 2013). In a more recent report, Rouprêt et al (2013) showed a reclassification rate for substaging of only $16 \%$ after central review of 587 HGT1 BC tumour sets from a multicentre data set. Other methods to substage HGT1 have been described using either millimetric evaluation of the depth of invasion (Cheng et al, 1999; Chang et al, 2012), measuring the size of the infiltrative tumour area as $\leqslant$ or $>1$ high-power field (Cheng et al, 1999; Bertz et al, 2011) or describing the extent of invasion (microinvasive or extensive) (van der Aa et al, 2005; van Rhijn et al, 2012). These alternative systems, however, have all been studied retrospectively in single data sets of patients and have not yet been externally validated (Martin-Doyle et al, 2014). A head-to-head comparison among these approaches in a large data set unfortunately is unavailable to date. Nonetheless, the fact that substaging remained a robust prognostic factor in our series (three-fold increase risk of progression in the adjusted multivariable model, and five-fold increase in the univariate model), even though patients with HGT1a underwent a more conservative approach demonstrates the magnitude of negative impact associated with depth of invasion.

We report a $15.5 \%$ progression rate, which is lower than the recently published pooled results of $\sim 20 \%$ progression rate for this high-risk group of tumours (van den Bosch and Alfred Witjes, 2011; Gontero et al, 2014; Martin-Doyle et al, 2014). Progression rates for high-risk $\mathrm{BC}$ have typically been considered to be over $30 \%$ and up to $50 \%$, but more current data support that approximately one in five cases progress and will typically do so within 48 months of initial diagnosis (van den Bosch and Alfred Witjes, 2011). Our approach of proceeding with the second TUR after the 6-week induction of BCG (Orsola et al, 2010) was also used by Denzinger et al (2007) with an overall progression rate of $41 \%$ in 132 patients. We contend that the better outcome in our series might be attributable to a complete, deep, and radical initial TUR together with the exclusion of cases without clear muscularis propria in the TURBT specimen. It is possible the use of BCG (induction and maintenance) and the second TUR have also contributed an added therapeutic benefit. The combined influence of all these factors might explain the low rate of understaging we found in the second TUR (9.9\%) as well as the low rate of positive findings at 3 months (Orsola et al, 2010), but the limitations mentioned previously should also be taken into account. Mitomycin-C might have only played a minor role given that no impact on progression has been demonstrated with this agent in all randomised published trials. Also the proposed approach in delaying the second TUR makes it impossible to accurately 
Table 4a. Univariate analysis for progression; association of substaging, tumour pattern, size and whether patients had CIS with time to progression at 2 and 5 years (only showing variables with significant $P$-values)

\begin{tabular}{|c|c|c|c|c|c|c|}
\hline & $N$ & Prog & $\begin{array}{c}\text { Progression free } \\
\text { at } 2 \text { years }\end{array}$ & $\begin{array}{l}\text { Progression free } \\
\text { at } 5 \text { years }\end{array}$ & $\begin{array}{c}\text { Hazard ratio and } \\
95 \% \mathrm{Cl}\end{array}$ & $P$ \\
\hline Substaging & & & & & & 0.0004 \\
\hline $\begin{array}{l}\text { T1a } \\
\text { T1b }\end{array}$ & $\begin{array}{r}89 \\
110\end{array}$ & $\begin{array}{r}5 \\
26 \\
\end{array}$ & $\begin{array}{l}0.95(0.90,0.99) \\
0.81(0.72,0.87)\end{array}$ & $\begin{array}{l}0.80(0.71,0.86) \\
0.74(0.61,0.83)\end{array}$ & $\begin{array}{c}0.21 \text { ( } 0.08,0.54) \\
1 \text { (reference) }\end{array}$ & \\
\hline Tumour pattern & & & & & & 0.006 \\
\hline $\begin{array}{l}\text { Papillary } \\
\text { Solid }\end{array}$ & $\begin{array}{r}165 \\
34\end{array}$ & $\begin{array}{l}21 \\
10\end{array}$ & $\begin{array}{l}0.91(0.85,0.94) \\
0.73(0.55,0.85)\end{array}$ & $0.87(0.80,0.92)$ & $\begin{array}{c}0.37 \text { (0.17, 0.78) } \\
\quad 1 \text { (reference) }\end{array}$ & \\
\hline Tumour size & & & & & & 0.04 \\
\hline $\begin{array}{l}<3 \mathrm{~cm} \\
>3 \mathrm{~cm}\end{array}$ & $\begin{array}{r}113 \\
86\end{array}$ & $\begin{array}{l}12 \\
19\end{array}$ & $\begin{array}{l}0.91(0.84,0.95) \\
0.83(0.73,0.90)\end{array}$ & $\begin{array}{l}0.87(0.75,0.93) \\
0.76(0.64,0.85)\end{array}$ & $\begin{array}{c}0.59(0.35,0.99) \\
1 \text { (reference) }\end{array}$ & \\
\hline $\mathrm{CIS}$ & & & & & & $<0.0001$ \\
\hline $\begin{array}{l}\text { Yes } \\
\text { No }\end{array}$ & $\begin{array}{r}56 \\
143 \\
\end{array}$ & $\begin{array}{l}18 \\
13 \\
\end{array}$ & $\begin{array}{l}0.71(0.57,0.81) \\
0.94(0.89,0.97)\end{array}$ & $\begin{array}{l}0.60(0.39,0.76) \\
0.90(0.83,0.95)\end{array}$ & $\begin{array}{c}1 \text { (reference) } \\
0.23 \text { (0.11, 0.48) }\end{array}$ & \\
\hline
\end{tabular}

Table 4b. Multivariable analysis for progression; association of significant variables in univariate analysis together with lymphovascular invasion and gender were analysed

\begin{tabular}{|l|c|c|}
\hline & $\begin{array}{c}\text { Hazard ratio and } \\
\mathbf{9 5 \%} \mathrm{Cl}\end{array}$ & $\boldsymbol{P}$ \\
\hline Substaging (T1a) & $0.30(0.12,0.81)$ & $\mathbf{0 . 0 2}$ \\
\hline $\mathrm{CIS}$ (No) & $0.24(0.12,0.81)$ & $\mathbf{0 . 0 0 0 2}$ \\
\hline Size $(<3 \mathrm{~cm})$ & $0.41(0.19,0.87)$ & $\mathbf{0 . 0 2}$ \\
\hline Pattern (papillary) & $0.68(0.31,1.48)$ & 0.33 \\
\hline Lymphovascular invasion (yes) & $2.07(0.60,7.10)$ & 0.25 \\
\hline Gender (male) & $1.23(0.37,4.12)$ & 0.74 \\
\hline $\begin{array}{l}\text { Abbreviations: Cl= confidence interval; CIS = carcinoma in situ. P<0.05 represent } \\
\text { statistically significant values (shown in bold). }\end{array}$ \\
\hline
\end{tabular}

differentiate between true understaging and early invasive recurrence.

Our study goes on to corroborate previous observations that CIS is a strong prognostic factor with a two-fold increase in risk of progression (Sylvester et al, 2006). In our report, the impact was even stronger with a $0.23 \mathrm{HR}$ favouring lack of CIS. Interestingly, we observed a high rate of detection in those patients who, according to surgeon preference, underwent multiple random bladder biopsies. This adds to the debate of whether routine bladder biopsies, which we have previously defended (Orsola et al, 2010), should be standardised at the time of initial BC TUR (Millan-Rodriguez et al, 2000). The usefulness of random bladder biopsies in the broad population of NMIBC is controversial (Kiemeney et al, 1994), but our findings suggest that a high positive yield is obtained in HGT1 cases. Alternatively, the diagnosis of CIS is based on its detection in either peritumoral areas of the specimen or if suspicious areas are biopsied. This approach, currently recommended by guidelines (American Urological Association, 2007; Babjuk et al, 2013), is highly limited by interpretation and likely leads to underdetection of true CIS, even though fluorescence-guided TURBT might improve identification of suspicious areas of CIS (Witjes et al, 2014). Finally, the findings of our study suggest that larger tumours and those with a solid pattern are associated with a worse outcome in HGT1, are consistent with the relevance of these parameters in the broader NMIBC population. Combining these factors we observed that patients with T1b tumours that were larger than $3 \mathrm{~cm}$ and associated with CIS were 4.8 times more likely to progress than the rest.

We failed to demonstrate a worse prognosis for LVI and for females in any of the outcomes. The incidence of LVI was very low
Table 4c. Combined risk for the association of T1b, larger tumour size and associated CIS

\begin{tabular}{|c|c|c|}
\hline & $\begin{array}{c}\text { Hazard ratio and } \\
95 \% \mathrm{Cl}\end{array}$ & $P$ \\
\hline Substaging (T1a) & $0.25(0.12,0.52)$ & 0.0002 \\
\hline CIS (no) & $0.28(0.11,0.73)$ & 0.009 \\
\hline Size $(<3 \mathrm{~cm})$ & $0.40(0.19,0.84)$ & 0.014 \\
\hline
\end{tabular}

(under 5\%) and, because its effects have been noted to correlate with depth of LP invasion, it is unclear whether LVI independently predicts outcome, or whether its detrimental impact is already captured by pathologic information on substaging (Martin-Doyle et al, 2014). Regarding gender, large population-based studies may be required to confirm a worse prognosis of females that has been suggested previously (Palou et al, 2012).

In summary, our report proposes a novel approach for HGT1 $\mathrm{BC}$ based on the selection of patients who will most benefit from a second TUR, specifically those with deep invasion of the MM (T1b). The main clinical implication of separately identifying almost half of HGT1 cases with T1a substaging as having a low (4\%) progression rate is that they can be spared a second endoscopic procedure with no harm. More accurate risk stratification incorporating depth of invasion, associated CIS, and tumour size would enable improved resource allocation for reTUR. It would also help identify optimal candidates for prompt cystectomy, namely $\mathrm{T} 1 \mathrm{~b}$ tumours larger than $3 \mathrm{~cm}$ and with associated CIS. If the one in five HGT1 patients who will eventually develop a muscle invasive $\mathrm{BC}$ could be identified after diagnostic TUR, then cystectomy could be offered more selectively. Also, overtreatment and the morbidity and anxiety of undergoing additional procedures could be spared in patients with more indolent prognosis. Our results further support the notion that the 'rule of thirds for HGT1' (i.e., one-third will never recur, one-third will require deferred cystectomy, and one-third will die of disease) is currently outdated.

Given the low impact of available scoring systems and biological markers (van Rhijn et al, 2012), and in view of this data, depth of invasion might be considered as the strongest prognostic factor for progression in HGT1. In addition, recent evidence suggests that histopathological classification into pTa, pT1a, and pT1b can be translated into a molecular signature, reflecting progressive dysregulation to more invasive stages (Descotes et al, 2013). Based on the prognostic impact of $\mathrm{T} 1$ substaging in the present and 
A

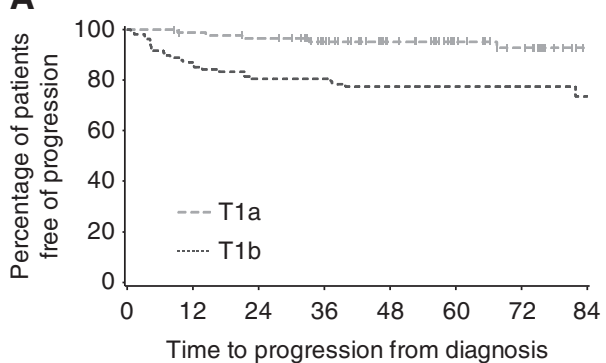

C

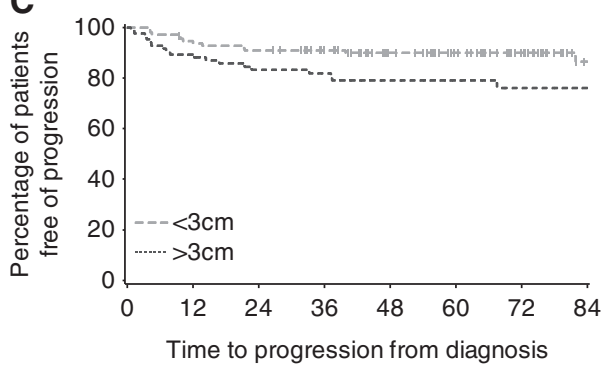

B

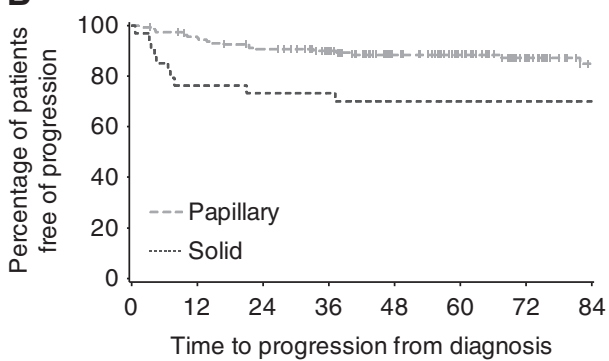

D

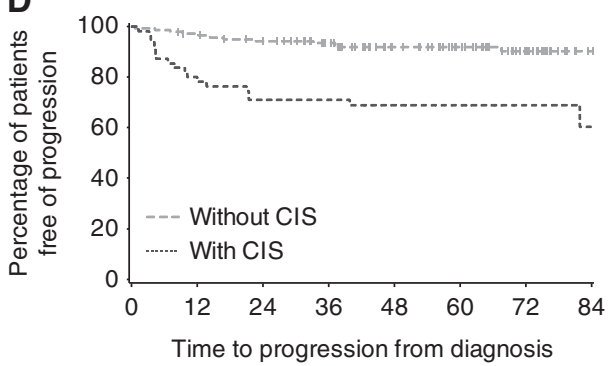

Figure 2. (A) Association of substaging and time to progression. (B) Association of tumour pattern and time to progression. (C) Association of tumour size and time to progression. (D) Association of CIS and time to progression.

previous studies, we believe there is an argument for evolution of the current TNM classification. Together with tumour size and the detection of CIS an updated classification would help to identify the patients most suitable for cystectomy. Randomised control trials to evaluate the positive impact of this subclassification of tumours would also be beneficial.

\section{CONCLUSIONS}

With this contemporary approach for the management of HGT1 $\mathrm{BC}$, in which the strategy of complete initial TUR + MitC + BCG is only followed by a second TUR in T1b cases, low recurrence and progression rates $(28.5 \%$ and $15.5 \%$, respectively) are achieved. Together with LP substaging (T1a vs T1b), tumour size and associated CIS are also prognostic factors for progression, which should be contemplated in future strategies and aid in the selection of patients for cystectomy.

\section{CONFLICT OF INTEREST}

The authors declare no conflict of interest.

\section{REFERENCES}

American Urological Association (2007) Guidelines for the management of non-muscle invasive bladder cancer (stages Ta, T1, and TIS): 2007 update. Aziz A, May M, Burger M, Palisaar RJ, Trinh QD, Fritsche HM, Rink M, Chun F, Martini T, Bolenz C, Mayr R, Pycha A, Nuhn P, Stief C, Novotny V, Wirth M, Seitz C, Noldus J, Gilfrich C, Shariat SF, Brookman-May S, Bastian PJ, Denzinger S, Gierth M, Roghmann F. PROMETRICS 2011 research group (2013) Prediction of 90-day mortality after radical cystectomy for bladder cancer in a Prospective European Multicenter Cohort. Eur Urol 66(1): 156-163.

Babjuk M, Burger M, Zigeuner R, Shariat SF, van Rhijn BW, Compérat E, Sylvester RJ, Kaasinen E, Böhle A, Palou Redorta J, Rouprêt M (2013) EAU guidelines on non-muscle-invasive urothelial carcinoma of the bladder: update 2013. Eur Urol 64(4): 639-653.

Bertz S, Denzinger S, Otto W, Wieland WF, Stoehr R, Hofstaedter F, Hartmann A (2011) Substaging by estimating the size of invasive tumour can improve risk stratification in $\mathrm{pT} 1$ urothelial bladder cancer-evaluation of a large hospital-based single-centre series. Histopathology 59(4): $722-732$.

Bottke D, Golz R, Störkel S, Hinke A, Siegmann A, Hertle L, Miller K, Hinkelbein W, Wiegel T (2013) Phase 3 study of adjuvant radiotherapy versus wait and see in pT3 prostate cancer: impact of pathology review on analysis. Eur Urol 64(2): 193-198.

Chang WC, Chang YH, Pan CC (2012) Prognostic significance in substaging ofT1 urinary bladder urothelial carcinoma on transurethral resection. Am J Surg Pathol 36(3): 454-461.

Cheng L, Neumann RM, Weaver AL, Spotts BE, Bostwick DG (1999) Predicting cancer progression in patients with stage $\mathrm{T} 1$ bladder carcinoma. J Clin Oncol 17(10): 3182-3187.

Cottrell L, Nairn ER, Hair M (2007) Consistency of microstaging pT1 bladder transitional cell carcinoma. J Clin Pathol 60(6): 735-736.

Denzinger S, Otto W, Fritsche HM, Roessler W, Wieland WF, Hartmann A, Burger M (2007) Bladder sparing approach for initial T1G3 bladder cancer: Do multifocality, size of tumor or concomitant carcinoma in situ matter? A long-term analysis of 132 patients. Int J Urol 14(11): 995-999, discussion 999.

Descotes F, Dessen P, Bringuier PP, Decaussin M, Martin PM, Adams M, Villers A, Lechevallier E, Rebillard X, Rodriguez-Lafrasse C, Devonec M, Paparel P, Perrin P, Lazar V, Ruffion A (2013) Microarray gene expression profiling and analysis of bladder cancer supports the sub classification of the T1 tumours in T1a and T1b stages. BJU Int 113(2): 333-342.

Divrik RT, Sahin AF, Yildirim U, Altok M, Zorlu F (2010) Impact of routine second transurethral resection on the long-term outcome of patients with newly diagnosed pT1 urothelial carcinoma with respect to recurrence, progression rate, and disease-specific survival: a prospective randomised clinical trial. Eur Urol 58(2): 185-190.

Eble JN, Sauter G, Epstein JI, Sesterhenn IA (2006) World Health Organization Classification of Tumors. Tumors of the Urinary System and Genital Organs. IARC Press: Lyon.

Ferlay J, Steliarova-Foucher E, Lortet-Tieulent J, Rosso S, Coebergh JW, Comber H, Forman D, Bray F (2013) Cancer incidence and mortality patterns in Europe: estimates for 40 countries in 2012. Eur J Cancer 49(6): 1374-1403.

Gontero P, Sylvester R, Pisano F, Joniau S, Vander Eeckt K, Serretta V, Larré S, Di Stasi S, Van Rhijn B, Witjes AJ, Grotenhuis AJ, Kiemeney LA, Colombo R, Briganti A, Babjuk M, Malmström PU, Oderda M, Irani J, Malats N, Baniel J, Mano R, Cai T, Cha EK, Ardelt P, Varkarakis J, Bartoletti R, Spahn M, Johansson R, Frea B, Soukup V, Xylinas E, Dalbagni G, Karnes RJ, Shariat SF, Palou J (2014) Prognostic factors and risk groups in T1G3 non-muscle-invasive bladder cancer patients initially 
treated with Bacillus Calmette-Guérin: results of a retrospective multicenter study of 2451 patients. Eur Urol 67(1): 74-82.

Herr HW, Donat SM, Dalbagni G (2007) Can restaging transurethral resection of T1 bladder cancer select patients for immediate cystectomy? J Urol 177(1): 75-79, discussion 79.

Jakse G, Algaba F, Malmström P, Oosterlinck W (2004) A second-look TUR in T1 transitional cell carcinoma: why? Eur Urol 45(5): 539-546, discussion 546.

Kiemeney LA, Witjes JA, Heijbroek RP, Koper NP, Verbeek AL, Debruyne FM (1994) Should random urothelial biopsies be taken from patients with primary superficial bladder cancer? A decision analysis. Members of the Dutch South-East Co-Operative Urological Group. Br J Urol 73(2): 164-171.

Martin-Doyle W, Leow J, Orsola A, Cheng S, Bellmunt J (2014) Improving selection criteria for early cystectomy in high-grade T1 bladder cancer: A meta-analysis of 15,215 patients. J Clin Oncol (under edition).

Millan-Rodriguez F, Chechile-Toniolo G, Salvador-Bayarri J, Palou J, Vicente-Rodriguez J (2000) Multivariate analysis of the prognostic factors of primary superficial bladder cancer. J Urol 163(1): 73-78.

Orsola A, Cecchini L, Raventos CX, Trilla E, Planas J, Landolfi S, de Torres I, Morote J (2010) Risk factors for positive findings in patients with highgrade T1 bladder cancer treated with transurethral resection of bladder tumour (TUR) and bacille Calmette-Guerin therapy and the decision for a repeat TUR. BJU Int 105(2): 202-207.

Orsola A, Trias I, Raventós C, Español I, Cecchini L, Búcar S, Salinas D, Orsola I (2005) Initial high-grade T1 urothelial cell carcinoma: feasibility and prognostic significance of lamina propria invasion microstaging $(\mathrm{T} 1 \mathrm{a} / \mathrm{b} / \mathrm{c})$ in BCG-treated and BCG-non-treated patients. Eur Urol 48(2): 231-238, discussion 238.

Palou J, Sylvester RJ, Faba OR, Parada R, Peña JA, Algaba F, Villavicencio H (2012) Female gender and carcinoma in situ in the prostatic urethra are prognostic factors for recurrence, progression, and disease-specific mortality in T1G3 bladder cancer patients treated with bacillus CalmetteGuérin. Eur Urol 62(1): 118-125.

Pansadoro V, Emiliozzi P, de Paula F, Scarpone P, Pansadoro A, Sternberg CN (2002) Long-term follow-up of G3T1 transitional cell carcinoma of the bladder treated with intravesical bacille Calmette-Guérin: 18-year experience. Urology 59(2): 227-231.

Raj GV, Herr H, Serio AM, Donat SM, Bochner BH, Vickers AJ, Dalbagni G (2007) Treatment paradigm shift may improve survival of patients with high risk superficial bladder cancer. J Urol 177(4): 1283-1286, discussion 1286

Rouprêt M, Seisen T, Compérat E, Larré S, Mazerolles C, Gobet F, Fetissof F, Fromont G, Safsaf A, d'Arcier BF, Celhay O, Validire P, Rozet F, Irani J, Soulié M, Pfister C. Comité de Cancérologie de l'Association Française d'Urologie (2013) Prognostic interest in discriminating muscularis mucosa invasion (T1a vs T1b) in nonmuscle invasive bladder carcinoma: French National Multicenter Study with central pathology review. J Urol 189(6): 2069-2076.
Sfakianos JP, Kim PH, Hakimi AA, Herr HW (2014) The effect of restaging transurethral resection on recurrence and progression rates in patients with nonmuscle invasive bladder cancer treated with intravesical bacillus Calmette-Guérin. J Urol 191(2): 341-345.

Skolarus TA, Ye Z, Montgomery JS, Weizer AZ, Hafez KS, Lee CT, Miller DC, Wood DP, Montie JE, Hollenbeck BK (2011) Use of restaging bladder tumor resection for bladder cancer among Medicare beneficiaries. Urology 78(6): 1345-1349.

Sylvester RJ, van der Meijden AP, Oosterlinck W, Witjes JA, Bouffioux C, Denis L, Newling DW, Kurth K (2006) Predicting recurrence and progression in individual patients with stage Ta T1 bladder cancer using EORTC risk tables: a combined analysis of 2596 patients from seven EORTC trials. Eur Urol 49(3): 466-465, discussion 475-477.

van den Bosch S, Alfred Witjes J (2011) Long-term cancer-specific survival in patients with high-risk, non-muscle-invasive bladder cancer and tumour progression: a systematic review. Eur Urol 60(3): 493-500.

van der Aa MN, van Leenders GJ, Steyerberg EW, van Rhijn BW, Jöbsis AC, Zwarthoff EC, van der Kwast TH (2005) A new system for substaging pT1 papillary bladder cancer: a prognostic evaluation. Hum Pathol 36(9): 981-986.

van Rhijn BW, Liu L, Vis AN, Bostrom PJ, Zuiverloon TC, Fleshner NE, van der Aa MN, Alkhateeb SS, Bangma CH, Jewett MA, Zwarthoff EC, Bapat B, van der Kwast TH, Zlotta AR (2012) Prognostic value of molecular markers, sub-stage and European Organisation for the research and treatment of cancer risk scores in primary T1 bladder cancer. BJU Int 110(8): 1169-1176.

van Rhijn BW, van der Kwast TH, Alkhateeb SS, Fleshner NE, van Leenders GJ, Bostrom PJ, van der Aa MN, Kakiashvili DM, Bangma CH, Jewett MA, Zlotta AR (2012) A new and highly prognostic system to discern T1 bladder cancer substage. Eur Urol 61(2): 378-384.

Witjes JA, Babjuk M, Gontero P, Jacqmin D, Karl A, Kruck S, Mariappan P, Palou Redorta J, Stenzl A, van Velthoven R, Zaak D (2014) Clinical and cost effectiveness of hexaminolevulinate-guided blue-light cystoscopy: evidence review and updated expert recommendations. Eur Urol; e-pub ahead of print 4 July 2014; doi:10.1016/j.eururo.2014.06.037.

Xylinas E, Kent M, Kluth L, Pycha A, Comploj E, Svatek RS, Lotan Y, Trinh QD, Karakiewicz PI, Holmang S, Scherr DS, Zerbib M, Vickers AJ, Shariat SF (2013) Accuracy of the EORTC risk tables and of the CUETO scoring model to predict outcomes in non-muscle-invasive urothelial carcinoma of the bladder. Br J Cancer 109(6): 1460-1466.

This work is published under the standard license to publish agreement. After 12 months the work will become freely available and the license terms will switch to a Creative Commons AttributionNonCommercial-Share Alike 3.0 Unported License. 